\title{
Effects of cellobiose on cellulose colonization by a mesophilic, cellulolytic Clostridium (strain C401)
}

\author{
E. Gelhaye, A. Gehin, L. Benoit and H. Petitdemange* \\ University of Nancy I, Laboratory of Biological Chemistry I, BP 239, 54506 Vandoeuvre-lès-Nancy, France
}

(Received 4 May 1993; revised 17 June 1993; accepted 20 July 1993)

\begin{abstract}
When cultured on a mixture of cellobiose and cellulose, Clostridium $\mathbf{C 4 0 1}$ did not initially attach to cellulose but remained in the liquid phase. After cellobiose exhaustion, bacterial cells grew in association with the insoluble cellulose. Carboxymethylcellulase (CMCase) production on Avicel cellulose was four- to fivefold greater than on cellobiose, and cellulose-grown cells adhered to filter paper with an initial adhesion rate about four- to fivefold greater than did cellobiose-grown cells. Using tritiated thymidine incorporation as a measure of growth, it appeared that transfer of strain $\mathbf{C 4 0 1}$ from cellobiose to cellulose required an adaptation phase. An extracellular cellulase complex was isolated by affinity chromatography. This enzyme system is a multicomponent aggregate (molecular mass above $5 \mathrm{MDa}$ ), and yielded two major polypeptide bands by SDS-PAGE having molecular masses of 130 and $70 \mathrm{kDa}$. Cellobiose strongly inhibited Avicelase activity and slightly inhibited p-nitrophenylcellobiose hydrolysis (pNPCbase), but had no effect on the CMCase activity of the cellulase complex. In addition, polyclonal antibodies, raised against the purified $130 \mathrm{kDa}$ protein inhibited Avicelase activity, but not CMCase and pNPCbase activities.
\end{abstract}

\section{Introduction}

The mesophilic, cellulolytic Clostridium $\mathrm{C} 401$ which was isolated with nine other strains from a municipal solid waste digester (Benoit et al., 1992), produces extracellular cellulases, and is able to degrade crystalline cellulose extensively. Previous experiments, using tritiated thymidine incorporation, demonstrated that growth of strain C401 on cellulose occurred only when bacteria were attached to the substrate (Gelhaye et al., 1992a). Adhesion of strain C401 to cellulose is a specific process which is regulated by the presence of cellobiose (Gelhaye et al., 1993a). Cellobiose, the major end-product of cellulolysis, is known to repress the synthesis of activity for crystalline cellulose hydrolysis (Avicelase) by the thermophilic Clostridium thermocellum (Johnson et al., 1985). Furthermore, the predominant forms of the bacterial cellulases detected in the culture supernatant were affected by the nature of the substrate (Saddler $\&$ Khan, 1981) and this has also been shown for strain C401 (Cailliez et al., 1993). However, the regulation of cellulase production in mesophilic, cellulolytic clostridia has not been extensively analysed and no study on the

*Author for correspondence. Tel. +3383912053 ; fax +338391 2550 .

Abbreviations: CMC, carboxymethylcellulose; CMCase, carboxymethylcellulase; pNPCbase, $p$-nitrophenylcellobiosidase. regulation of cellulose colonization has been published. The aim of the present work was to characterize some effects of cellobiose on cellulose colonization by Clostridium C401.

\section{Methods}

Organism and culture conditions. Strain C401 was grown anaerobically in the medium of Benoit et al. (1992) to which the desired carbon source was added as described below.

Thymidine incorporation rate. Batch cultures $(9 \mathrm{ml})$ were grown as described previously (Gelhaye et $a l ., 1993 b$ ) in $\mathrm{N}_{2}$-flushed Hungate tubes containing Avicel cellulose $(0.75 \%, w / v)$ with or without cellobiose $(0.2 \%, w / v)$. In the course of fermentation, filter-sterilized thymidine (Amersham) (labelled and unlabelled) was added so that the final concentration was $42 \mu \mathrm{M}$ and $2 \cdot 1 \mu \mathrm{Ci} \mathrm{m}^{-1}\left(77 \mathrm{kBq} \mathrm{ml}^{-1}\right)$. At this concentration, the incorporation of added thymidine into DNA, defined as the cold trichloroacetic acid (TCA)-precipitable fraction, was not limiting (Gelhaye et al., 1992a). At the end of the time course $(2 \mathrm{~h})$, separation of attached and free cells was performed as described previously (Gelhaye et al., 1993b). The TCA extraction and radioactivity measurement were performed immediately using the method of Fuhrman \& Azam (1982). Values obtained were converted to d.p.m. (ml culture) $)^{-1}$.

Biomass detection. The determination of attached and free biomass was based on bacterial protein estimation as described by Bensadoun \& Weinstein (1976). The values obtained were converted to $\mathrm{mg}$ cells $\mathrm{ml}^{-1}$. Calibrations were performed with cellobiose-grown cells to estimate the relationship between the optical density, dry weight and protein content of the cells.

Reducing sugars. The quantity of reducing sugars was determined by the method described by Miller (1959). In several cases, sugars in the 
supernatant fluid were detected by HPLC (SP8430 Spectra-Physics) using a polypore $\mathrm{H}$ column.

Analytical methods. To detect ethanol and acetate, samples were centrifuged at $13000 \mathrm{~g}$ for $15 \mathrm{~min}$. A $1 \mathrm{ml}$ sample of culture supernatant was acidified with $50 \mu \mathrm{ln}$-butanol in $6 \mathrm{M}-\mathrm{HCl}$. A portion $(2 \mu \mathrm{l})$ of the acidificed supernatant was injected into an Intersmat IGC $121 \mathrm{FL}$ gas chromatograph equipped with a flame ionization detector. Separation took place in a $2 \mathrm{~m}$ glass column packed with Porapack $\mathrm{Q}, 100 / 120$ mesh. Nitrogen was used as the carrier gas. Injector and detector temperatures were $230^{\circ} \mathrm{C}$, and column temperature was $175^{\circ} \mathrm{C}$. The analysis of chromatographic data was done by an Intersmat ICR 1B integrator.

Lactate (D and L) was detected spectrophotometrically with the appropriate enzyme kit (Boehringer Mannheim).

Bacterial adhesion. In cellobiose culture, bacteria were harvested in the exponential phase of growth by centrifugation and washed twice with 50 mM-sodium phosphate buffer, $\mathrm{pH} 7.8$. In Avicel cellulose culture $(50 \mathrm{ml})$, cellulose and bacteria in exponential phase were harvested by centrifugation. The supernatant was discarded and the pellet was resuspended in $50 \mathrm{ml} 50 \mathrm{~mm}$-Tris/ $\mathrm{HCl}$ buffer $(\mathrm{pH} \mathrm{7.8)}$ to dislodge attached cells, shaken and the cellulose allowed to settle. The treatment was repeated and both supernatants [containing about $85 \%$ of the initial biomass (Gelhaye et al., 1993a)] were pooled and centrifuged. Pelleted cells were suspended in sodium phosphate buffer, $\mathrm{pH} 7 \cdot 8$.

Measurements of adhesion to filter paper were performed as described previously (Gelhaye et al., 1992b).

Cellulase complex isolation. Strain C401 $(500 \mathrm{ml})$ was grown on Avicel cellulose $(0 \cdot 1 \%, \mathrm{w} / \mathrm{v})$. Bacteria were pelleted by centrifugation in the late phase of growth $(96 \mathrm{~h})$. The supernatant fluid was concentrated by ultrafiltration using an Amicon PM10 membrane. This concentrate was applied to an Avicel cellulose-packed column $(1.5 \times 30 \mathrm{~cm})$ equilibrated with $100 \mathrm{~mm}-\mathrm{Tris} / \mathrm{HCl}$ buffer $(\mathrm{pH} 7.8)$. The column was washed with the same buffer to elute the unattached fraction. The adhered fraction (cellulase) was eluted with deionized water ( $\mathrm{pH}$ 6.4). In several cases, the cellulase fraction was concentrated by ultrafiltration and fractionated on a gel filtration column (Sepharose CL4B, $2.5 \times 50 \mathrm{~cm}$ ) equilibrated and eluted with deionized water (pH 6.4).

Enzyme activities. Endoglucanase activity (CMCase) was determined by incubating the enzyme preparation $(100 \mu \mathrm{l})$ with carboxymethylcellulose (CMC) for $30 \mathrm{~min}$ and measuring reducing sugars as described by Miller et al. (1960). Each reaction mixture contained Tris/ $\mathrm{HCl}$ buffer ( $\mathrm{pH} \mathrm{7,0.075} \mathrm{mmol);} \mathrm{CMC}(20 \mathrm{mg})$, distilled water and enzyme preparation in a total volume of $2.0 \mathrm{ml}$.

Avicelase activity was determined by incubating the enzyme preparation $(100 \mu \mathrm{l})$ with the following mixture (in a total volume of $5 \mathrm{ml}$ ): $0.15 \mathrm{mmol}$ Tris $/ \mathrm{HCl}$ buffer $(\mathrm{pH} \mathrm{7)} ; 1.33 \mathrm{mg}$ Avicel; $50 \mu \mathrm{mol}$ dithiothreitol; $25 \mu \mathrm{mol} \mathrm{CaCl}_{2}$ and distilled water as described by Cavedon et al. (1990). At the end of incubation ( $72 \mathrm{~h})$, insoluble material was removed by centrifugation and the amount of reducing sugars was measured as described by Miller et al. (1960).

The $p$-nitrophenylcellobiosidase (pNPCbase) was measured by incubating the enzyme preparation $(100 \mu \mathrm{l})$ with $p$-nitrophenylcellobioside for $1 \mathrm{~h}$ as described previously (Cailliez et al., 1993). Each reaction mixture contained Tris/ $\mathrm{HCl}$ buffer $(\mathrm{pH} 7,0.03 \mathrm{mmol}), p$ nitrophenylcellobioside $(1.0 \mathrm{mg})$, distilled water and enzyme preparation $(100 \mu \mathrm{l})$ in a total volume of $1.0 \mathrm{ml}$.

To measure the effects of cellobiose on the three activities, cellobiose at different concentrations was added to these reaction mixtures.

SDS-PAGE and zymogram. Polypeptides were separated by SDSPAGE. Electrophoresis in polyacrylamide slab gels (stacking gel, $5 \%$, $\mathrm{w} / \mathrm{v}$, acrylamide; running gel, $12 \%$ acrylamide) was performed in Tris $(25 \mathrm{~mm}) /$ glycine (192 mM) buffer ( $\mathrm{pH} 8.3)$ in the presence of SDS $(0.1 \%$ w/v) with the gel system of Laemmli (1970).

CMCase zymograms were prepared by using $0.1 \%$ CMC copolymerized with $7.5 \%$ polyacrylamide as described by Shoseyov \& Doi (1990), without first removing SDS. CMCase activities were visualized with Congo red after a $15 \mathrm{~h}$ incubation at $37^{\circ} \mathrm{C}$. Washing gels to remove SDS did not alter the banding pattern on the zymograms.

$P 1$ antiserum production. Isolated cellulase $(1 \mathrm{mg})$ was resolved by preparative SDS-PAGE. The gel was stained with Coomassie blue and the $130 \mathrm{kDa}(\mathrm{P} 1)$ band was cut out and used as an immunogen. P1 preparation $(100 \mu \mathrm{g})$ was mixed with Freund's complete adjuvant and injected into New Zealand White rabbits. The second and third injections were done after 2 week and 1 month intervals using the same quantity of protein. A final injection of $100 \mu \mathrm{g}$ was done 2 months after the third injection and the serum was collected $10 \mathrm{~d}$ later. Western blot analysis was performed to confirm specific interaction between antiserum and $\mathrm{P} 1$ at 1:500 dilution.

CMCase, pNPCbase and Avicelase were tested in the presence and absence of antiserum. A preparation of cellulase complex $(100 \mu \mathrm{l}$, $\left.2 \mathrm{mg} \mathrm{ml}^{-1}\right)$ was mixed with different volumes of antiserum $(0 \cdot 5,1$ or $2 \mu \mathrm{l})$. After this pre-incubation step (30 min), CMCase, pNPCbase and Avicelase activities were tested as described above.

\section{Results and Discussion}

\section{Effects of cellobiose on cellulose colonization}

Previous studies have shown that growth of strain C401 on Avicel cellulose occurs when bacteria are attached to their substrate (Gelhaye et al., 1992a). The presence of cellobiose strongly modified the colonization of Avicel cellulose by strain C401 (Fig. 1). The fermentation can be divided into four stages.

In the first stage $(0-15 \mathrm{~h})$, growth occurred in the liquid phase containing cellobiose without bacterial attachment to cellulose (Fig. $1 a-c$ ). The doubling time $(4 \mathrm{~h})$ of the free population corresponded to growth on cellobiose alone (Benoit et al., 1992).

In the second phase (15-25 h), bacteria were found attached to the cellulose (Fig. $1 a, b$ ). About $60 \%$ of the biomass found free in the first stage, was attached to the cellulose after $25 \mathrm{~h}$. The growth rate of the attached population (doubling time about $6 \mathrm{~h}$ ) was slightly greater than that on cellulose alone ( $8 \mathrm{~h}$; Gelhaye et al., 1992a), suggesting that growth occurred on the cellobiose still present in the culture (Fig. 1c).

Between 25 and $50 \mathrm{~h}$, the thymidine incorporation rate decreased within the attached biomass without increase in the free population (Fig. $1 b$ ). This decreased growth was correlated with a cessation of metabolite production (Fig. 1d) and exhaustion of the cellobiose (Fig. 1c). Apparently, adaptation to cellulose degradation occurred.

In the last stage (after $50 \mathrm{~h}$ ), an increase of the thymidine incorporation rate was observed in both attached and free cells (Fig. 1b). The slight increase of the free biomass did not explain the observed burst. 

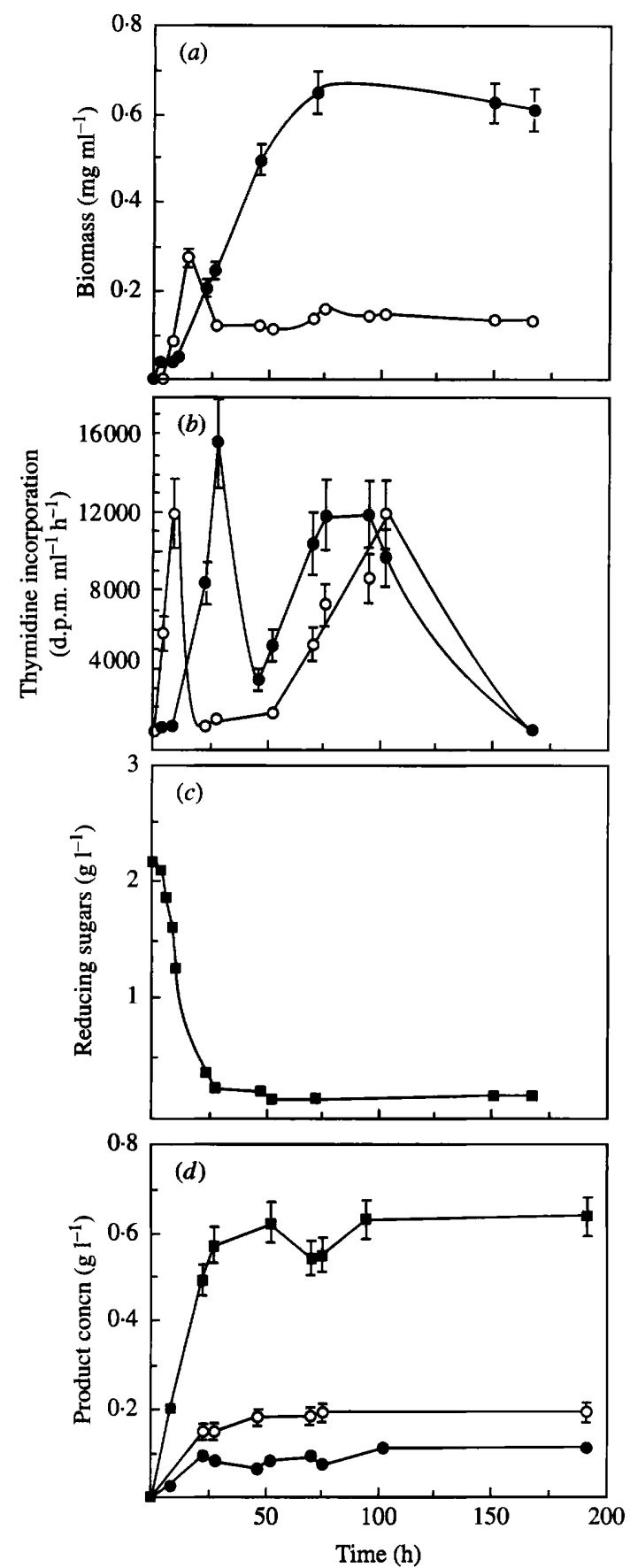

Fig. 1. Effects of cellobiose $(0.2 \%)$ on cellulose $(0.75 \%)$ colonization by strain C401. (a) Formation of attached $(O)$ and free $(O)$ biomass; $(b)$ thymidine incorporation into attached $(O)$ and free $(O)$ cells; $(c)$ reducing sugar concentration; $(d)$ acetate $(\square)$, ethanol $(O)$ and lactate (O) production. Each point is the mean \pm SD of four determinations from two separate cultures.

Analysis by HPLC of the supernatant did not reveal sugar concentrations above $0.05 \mathrm{~g}^{-1}$ (data not shown). At the same time, a slight decrease in the amount of acetate (Fig. $1 d$ ) was observed, suggesting that it was used after the exhaustion of cellobiose (Fig. 1c). These

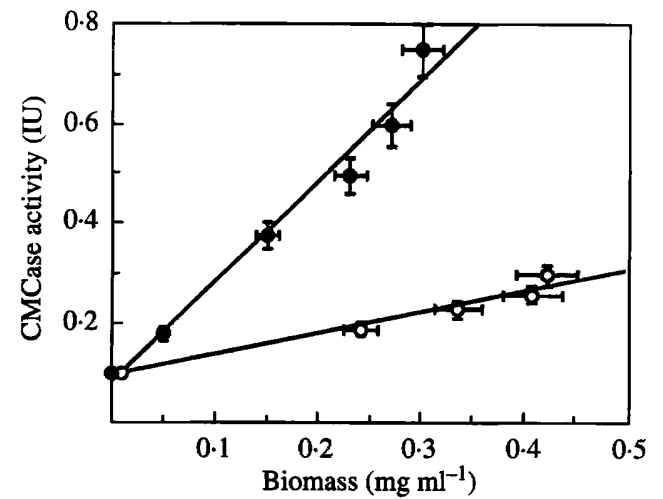

Fig. 2. CMCase activity as a function of cell dry weight during the exponential phase of growth in cellulose $(O)$ or in cellobiose $(O)$. Each point is the mean $\pm S D$ of four determinations from two separate cultures.

results could indicate that the free cells had exhausted their carbon source. The obligatory completion of initiated rounds of DNA replication and cell division could explain the changes in the rate of thymidine incorporation into free cells (Wanner \& Egli, 1990; Gelhaye et al., 1993b). Furthermore, the consumption of acetate by bacteria depleted of their carbon source has been reported for several micro-organisms without additional biomass formation (Niven et al., 1977; Anderson \& Von Meyenburg, 1980). At the same time, the growth of the attached population was low (doubling time about $15 \mathrm{~h}$ ), suggesting that bacteria were in the decelerating phase, possibly due to an accumulation of end-products or to a fall of $\mathrm{pH}$.

\section{Effects of cellobiose on CMCase production}

CMCase production was measured in Avicel cellulose $(0.75 \%, \mathrm{w} / \mathrm{v})$ and cellobiose $(0.5 \%, \mathrm{w} / \mathrm{v})$ cultures. In both cases, the total activity of CMCase paralleled growth. However, as shown in Fig. 2, the specific activity was about four- to fivefold greater during growth on Avicel cellulose [ $2 \mathrm{IU}(\mathrm{mg} \text { cells })^{-1}$ ] than on cellobiose [0.5 IU (mg cells $\left.)^{-1}\right]$. In the presence of Avicel and cellobiose $(0.5 \%, \mathrm{w} / \mathrm{v})$, the lowered CMCase specific activity $\left[0.5 \mathrm{IU}(\mathrm{mg} \text { cells })^{-1}\right]$ confirmed that cellobiose regulates the production of CMCase by strain C401. Furthermore, this regulation could explain, at least in part, the adaptation phase to cellulose degradation observed in cellobiose-grown cells (Fig. 1).

\section{Effects of cellobiose on strain C401 adhesion}

Cellobiose-grown cells adhered to filter paper (Fig. 3), with an initial adhesion rate, calculated using the initial slope of the plot, of $7 \times 10^{-4} \mathrm{mg} \mathrm{cm}^{-2} \mathrm{~min}^{-1}$. The rate was about four- to fivefold greater with cellulose-grown cells 


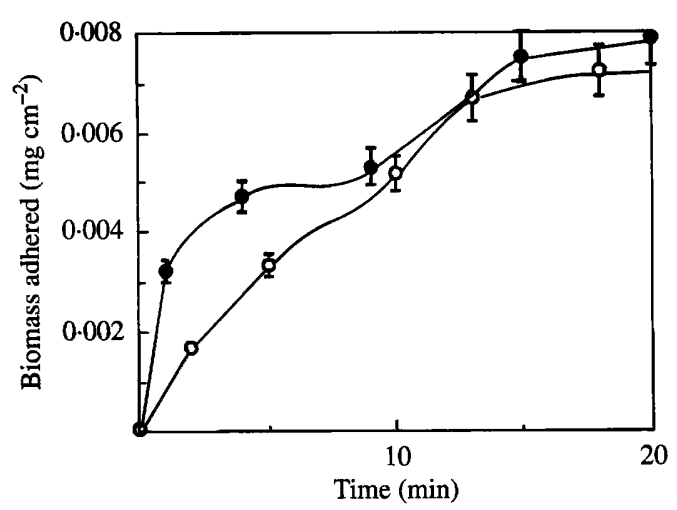

Fig. 3. Adhesion of cellulose- $(\bullet)$ and cellobiose- $(O)$ grown cells to Whatman no. 1 filter paper. The total biomass was $0.25 \mathrm{mg}$ dry wt $\mathrm{ml}^{-1}$. Each point is the mean $\pm \mathrm{SD}$ of four determinations from two separate experiments.

$\left(32 \times 10^{-4} \mathrm{mg} \mathrm{cm}^{-2} \mathrm{~min}^{-1}\right)$. Thus, the production of adhesion factor(s) was limited in cellobiose-grown culture. It is interesting to note that the same sharp decline (four- to fivefold) occurred in both CMCase activity and adhesion factor(s), in cellobiose-grown cultures compared with cellulose-grown cultures. These results suggested that cellulase synthesis and adhesion were coregulated.

Previous studies demonstrated that adhesion of cellulose-grown cells was regulated by cellobiose (Gelhaye et al., 1993a). Effects of cellobiose were the same with cellobiose-grown cells. Bacterial adhesion was enhanced at cellobiose concentrations between 0.05 and $0.15 \%$ $(w / v)$. Conversely, at higher concentrations, cellobiose inhibited adhesion of strain C401. These results could explain the changes in bacterial adhesion observed in the first stages $(0-25 \mathrm{~h})$ of the fermentation described above (Fig. 1).

These results suggested that cellobiose plays a major role in the regulation of cellulose colonization by strain $\mathrm{C} 401$, in particular concerning adhesion.

\section{Strain C401 cellulase complex}

The extracellular complex was isolated from the crude protein mixture by taking advantage of the extremely high affinity of the complex for cellulose. The cellulase complex could be washed from cellulose by deionized water. This eluted fraction contained $80 \%$ of the initial CMCase activity. When this fraction was applied on a Sepharose CL4B column, we observed a single major absorbance peak that eluted before thyroglobulin $(669 \mathrm{kDa})$. Molecular mass standards larger than thryoglobulin were not available, but we have estimated by extrapolation that the aggregate has a molecular mass above $5 \mathrm{MDa}$. The cellulase complex was resolved by SDS-PAGE to reveal two major polypeptide bands

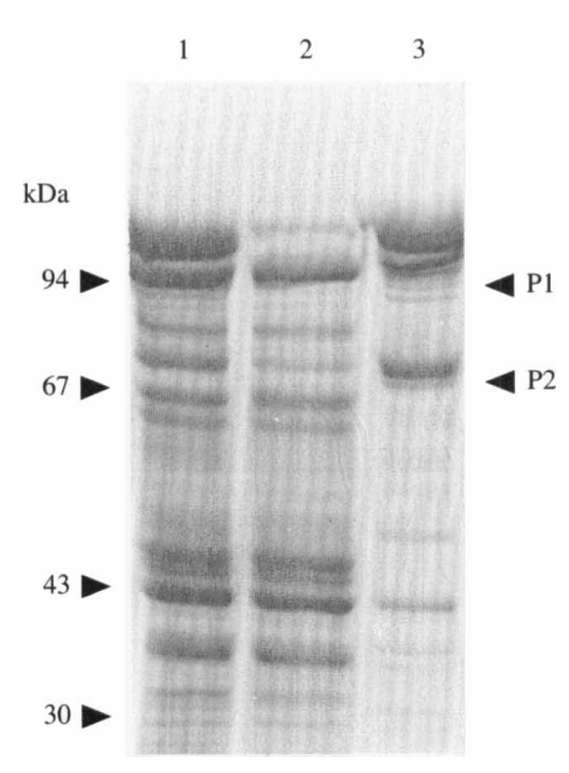

Fig. 4. SDS-PAGE analysis of the affinity-purified cellulase complex. Lanes 1 , whole extracellular extract $(10 \mu \mathrm{l}) ; 2$, non-attached fraction $(10 \mu \mathrm{l}) ; 3$, fraction eluted with deionized water $(10 \mu \mathrm{l})$. All fractions were concentrated to the same volume. $\mathrm{P} 1$ and $\mathrm{P} 2$ are defined in the text.

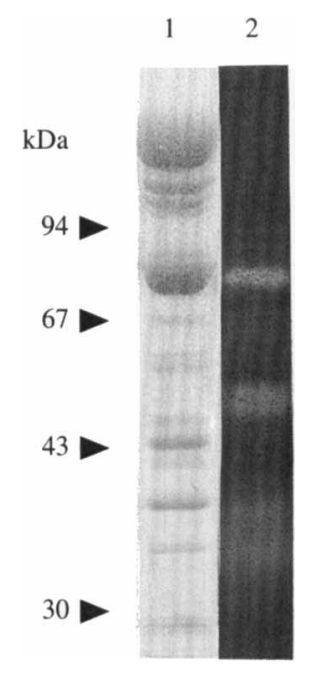

Fig. 5. CMC/SDS-PAGE analysis of the cellulase complex (see Fig. 4, lane 3). Lanes 1, Coomassie blue staining; 2, CMCase activity staining.

having molecular masses of $130 \mathrm{kDa}(\mathrm{P} 1)$ and $70 \mathrm{kDa}$ (P2), and several minor polypeptides (Fig. 4, lane 3). Consequently, as with many cellulolytic clostridia (Lamed et al., 1987; Lamed \& Bayer, 1988), the strain C401 cellulase was a multiprotein complex composed of different subunits having a heterogeneous stoichiometry.

A test for CMCase activity was performed on the proteins separated by SDS-PAGE (Fig. 5, lane 2). Several CMCase activities were detected but the major protein P1 had no detectable hydrolytic activity. 


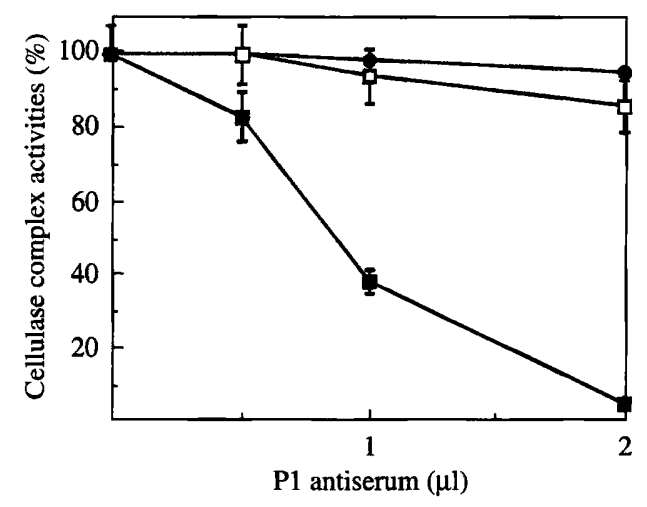

Fig. 6. Effect of P1 antiserum on pPNPCbase ( $)$, CMCase ( $\square$ ) and Avicelase ( $\mathbf{C}$ ) activities of the cellulase complex. Each tested system contained $100 \mu \mathrm{l}$ of cellulase complex $\left(2 \mathrm{mg} \mathrm{ml}^{-1}\right)$. Each point is the mean \pm SD of four determinations from two separate experiments.

\section{Effect of $P 1$ antiserum on cellulase activity}

We tested the effect of the P1 antiserum on the cellulase complex to determine whether it could inhibit specific enzyme activities. The antiserum was mixed with the isolated cellulase complex $\left(2 \mathrm{mg} \mathrm{ml}^{-1}\right)$ and this mixture was tested for Avicelase, CMCase, and pNPCbase activities (Fig. 6). Antiserum inhibited Avicelase activity but not CMCase and pNPCbase activities of the complex.

Consequently, as with many cellulolytic clostridia, strain $\mathrm{C} 401$ produces a cellulase complex which is able to degrade crystalline cellulose. Furthermore, the major protein of the complex (P1) showed characteristics similar to that of C. cellulovorans P170 (CbpA), i.e. high affinity for cellulose, no apparent hydrolytic activity, and its presence is necessary for Avicelase activity (Shoseyov \& Doi, 1990).

\section{Effects of cellobiose on the strain C401 cellulase}

Effects of cellobiose were observed on the CMCase, pNPCbase and Avicelase activities of the strain C401 cellulase complex (Fig. 7). Cellobiose strongly inhibited Avicelase activity, and inhibited pNPCbase activity to some extent, but did not inhibit CMCase activity. These results suggested that cellobiose inhibited a factor which was not implicated in CMCase and pNPCbase activities, but which was necessary for the degradation of crystalline cellulose.

Strain C401 produces a cellulase complex which resembles that of $C$. cellulovorans (Shoseyov \& Doi, 1990). This study demonstrated that cellobiose has an important function in the regulation of cellulose colonization by strain $\mathrm{C} 401$ at several levels. Cellobiose regulates (i) the production of CMCase activity, (ii) the production of bacterial adhesion factor(s), (iii) bacterial

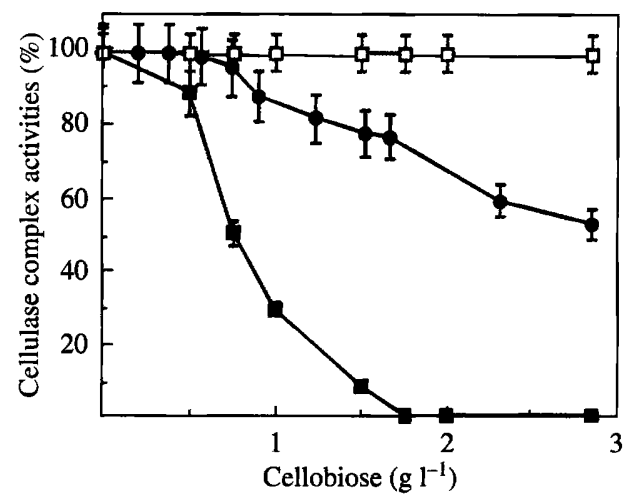

Fig. 7. Effects of cellobiose on pPNPCbase (O), CMCase ( $\square$ ) and Avicelase ( $\square$ ) activities of the cellulase complex. Each tested system contained $100 \mu \mathrm{l}$ of cellulase complex $\left(2 \mathrm{mg} \mathrm{m}^{-1}\right)$. Each point is the mean \pm SD of four determinations from two separate experiments.

adhesion to cellulose, and (iv) the Avicelase activity of the cellulase complex. Furthermore, the shift of growth of strain C401 from cellobiose to cellulose required an adaptation phase. Further investigations are required to characterize the factors implicated in these observed regulations.

This work was supported by a fellowship to E. G. from the Agence de l'Environnement et de la Maîtrise de l'Energie (ADEME) and from Gaz de France.

\section{References}

Anderson, K. B. \& Von Meyenburg, K. (1980). Are growth rates of Escherichia coli in batch cultures limited by respiration? Journal of Bacteriology 144, 114-123.

Benoit, L., Cailliez, C., Petitdemange, E. \& Gitton, J. (1992). Isolation of cellulolytic mesophilic Clostridia from a municipal solid waste digestor. Microbiology Ecology 23, 117-125.

Bensadoun, A. \& Weinstein, D. (1976). Assay of proteins in the presence of interfering materials. Analytical Biochemistry 70, 241-250.

Cailliez, C., Benort, L., Gelhaye, E., Petitdemange, H. \& Raval, G. (1993). Solubilization of cellulose by mesophilic cellulolytic Clostridia isolated from a municipal solid-waste digestor. Bioresource Technology 43, 77-83.

Cavedon, K., Leschine, S. B. \& Canale-Parola, E. (1990). Cellulase system of a free-living, mesophilic Clostridium (strain C7). Journal of Bacteriology 172, 4222-4230.

FuHrman, J. A. \& AZAM, F. (1982). Thymidine incorporation as a measure of heterotrophic bacterioplankton production in marine surface waters: evaluation and field results. Marine Biology 66, 109-120.

Gelhaye, E., Petitdemange, H. \& Gay, R. (1992a). Characteristics of cellulose colonization by a mesophilic cellulolytic Clostridium (strain C401). Research in Microbiology 143, 891-895.

Gelhaye, E., Claude, B., Cailliez, C., Burle, S. \& Petitdemange, H. $(1992 b)$. Multilayer adhesion to filter paper of two mesophilic, cellulolytic Clostridia. Current Microbiology 25, 307-311.

Gelhaye, E. Benoit, L., Petitdemange, H. \& Gay, R. (1993a). Adhesive properties of five mesophilic, cellulolytic Clostridia isolated from the same biotope. FEMS Microbiology Ecology 102, 67-73.

Gelhaye, E., Petitdemange, H. \& Gay, R. (1993 $b$ ). Adhesion and growth rate of Clostridium cellulolyticum ATCC 35319 on crystalline cellulose. Journal of Bacteriology 175, 3452-3458. 
Johnson, E. A., Bouchot, F. \& Demain, A. L. (1985). Regulation of cellulase formation in Clostridium thermocellum. Journal of General Microbiology 131, 2303-2308.

LAEMMLI, U. K. (1970). Cleavage of structural proteins during the assembly of the head of bacteriophage T4. Nature, London 227, 680-685.

LAMED, R. \& BAYER, E. A. (1988). The cellulosome concept: exocellular/extracellular enzyme reactor centers for efficient binding and cellulolysis. In Biochemistry and Genetics of Cellulose Degradation, pp. 101-116. Edited by J. P. Aubert, P. Beguin \& J. Millet. New York and London: Academic Press.

Lamed, R., Naimar, J., Morgenstern, E. \& Bayer, E. A. (1987). Specialized cell surface structures in cellulolytic bacteria. Journal of Bacteriology 169, 3792-3800.

MiLLER, G. L. (1959). Use of dinitrosalicylic reagent for determination of reducing sugars. Analytical Chemistry 31, 426-428.
MilleR, G. L. R., BLum, W. E. \& BuRTon, A. L. (1960). Measurements of carboxymethylcellulase activity. Analytical Biochemistry 2, 127132.

Niven, D. F., Collins, P. A. \& Knowles, C. J. (1977). Adenylate energy charge during batch culture of Beneckea natriegens. Journal of General Microbiology 98, 95-108.

SADDLER, J. N. \& KAHN, A. W. (1981). Cellulolytic enzyme system of Acetivibrio cellulolyticus. Canadian Journal of Microbiology 27, 173-196.

Shoseyov, O. \& Dor, R. H. (1990). Essential $170 \mathrm{kDa}$ subunit for degradation of crystalline cellulose by Clostridium cellulovorans. Proceedings of the National Academy of Sciences of the United States of America 87, 2192-2195.

WANNER, U. \& EGLI, T. (1990). Dynamics of microbial growth and cell composition in batch cultures. FEMS Microbiology Reviews 75, $19-44$. 